\title{
Pre- and post- experimental manipulation assessments confirms the increase in number of birds due to the addition of nest boxes
}

Cecilia Cuatianquiz Lima, Constantino Macías Garcia

Secondary cavity nesting ( $\mathrm{SCN}$ ) birds breed in holes that they do not excavate themselves. This is possible where there are large trees whose size and age permits the digging of holes by primary excavators and only rarely happens in forest plantations, where we expected a deficit of both breeding holes and SCN species. We assessed whether the availability of tree cavities influenced the number of SCNs in two temperate forest types, and evaluated the change in number of SCNs after adding nest boxes. First, we counted all cavities within each of our 25-m radius sampling points in mature and young forest plots during 2009. We then added nest boxes at standardised locations during 2010 and 2011 and conducted fortnightly bird counts (January - October 2009-2011). In 2011 we added two extra plots of each forest type, where we also conducted bird counts. Prior to adding nest boxes, counts revealed more SCNs in mature than in young forest. Following the addition of nest boxes, the number of SCNs increased significantly in the points with nest boxes in both types of forest. Counts in 2011 confirmed the increase in number of birds due to the addition of nest boxes. Given the likely benefits associated with a richer bird community we propose that, as is routinely done in some countries, forest management programs preserve old tree stumps and add nest boxes to forest plantations in order to increase bird numbers and bird community diversity. 
2 Pre- and post- experimental manipulation assessments confirms the increase in number of

5 Instituto de Ecología. Universidad Nacional Autónoma de México, México, México

$6{ }^{2}$ Centro Tlaxcala de Biología de la Conducta, Universidad Autónoma de Tlaxcala, Tlaxcala,

7 México

8 Corresponding Author:

9 Constantino Macías Garcia

10 Ciudad de México, A. P. 70-275, C.P. 04510, México

11 maciasg@unam.mx 


\section{ABSTRACT}

13 Secondary cavity nesting (SCN) birds breed in holes that they do not excavate themselves. This

14 is possible where there are large trees whose size and age permits the digging of holes by primary

15 excavators and only rarely happens in forest plantations, where we expected a deficit of both

16 breeding holes and SCN species. We assessed whether the availability of tree cavities influenced

17 the number of SCNs in two temperate forest types, and evaluated the change in number of SCNs

18 after adding nest boxes. First, we counted all cavities within each of our $25-\mathrm{m}$ radius sampling

19 points in mature and young forest plots during 2009. We then added nest boxes at standardised

20 locations during 2010 and 2011 and conducted fortnightly bird counts (January - October 2009-

21 2011). In 2011 we added two extra plots of each forest type, where we also conducted bird

22 counts. Prior to adding nest boxes, counts revealed more SCNs in mature than in young forest.

23 Following the addition of nest boxes, the number of SCNs increased significantly in the points

24 with nest boxes in both types of forest. Counts in 2011 confirmed the increase in number of birds

25 due to the addition of nest boxes. Given the likely benefits associated with a richer bird

26 community we propose that, as is routinely done in some countries, forest management programs

27 preserve old tree stumps and add nest boxes to forest plantations in order to increase bird

28 numbers and bird community diversity. 
INTRODUCTION

30 Worldwide, $26 \%$ of land birds rely on the presence of tree cavities in the environment to nest or

31 roost (Newton, 1994; 1998). Of these, some dig cavities de novo (primary cavity excavators)

32 whereas others (secondary cavity nesters) depend on pre-existing cavities that either form

33 naturally or are previously dug by primary cavity excavators, mainly woodpeckers (Swallow,

34 Gutierrez \& Howard 1986; Brawn \& Balda, 1988; Newton, 1994; Martin \& Eadie, 1999; Martin,

35 Aitken \& Wiebe, 2004; Lohmus \& Remm, 2005; Remm, Lohmus \& Remm, 2006) or other birds

36 (e.g. European bee-eaters; Casas-Crivillé \& Valera, 2005). Additionally, the presence of other

37 organisms contributes to the creation of cavities (fungi, insects, amphibians, reptiles and

38 mammals), and some secondary cavity nesters can modify the cavity to suit their needs,

39 especially in soft wood (Newton, 1994; Martin, Aitken \& Wiebe, 2004; Martin, Norris \& Drever,

40 2006; Sánchez, Cuervo \& Moreno, 2007; Lambrechts et al., 2010). Nevertheless, cavities are

41 often a limiting resource and their availability and suitability can drive population processes in

42 the species that use them, particularly among secondary cavity nesters (Brawn \& Balda, 1988;

43 Newton, 1994; Martin, Aitken \& Wiebe, 2004; Aitken \& Martin, 2012). Since cavity nesting

44 species often have specific requirements, cavities that are appropriate for one species may not be

45 suitable for others, thus increasing the intensity of both intra and interspecific competition

46 (Dhondt, 2012).

Some researchers report that the availability of suitable cavities depends on the attributes

48 of the trees present in a given area, including their size, age, architecture, hardness and density

49 (van Balen et al., 1982; Martin, Aitken \& Wiebe, 2004; Martin, Norris \& Drever, 2006; Sánchez,

50 Cuervo \& Moreno, 2007; Cornelius et al., 2008; Lambrechts, Schatz \& Borgault, 2008; Cockle,

51 Martin \& Drever, 2010; Lambrechts et al., 2010). Several studies have shown that in undisturbed

52 forest the number of suitable nesting cavities increases with tree age, with snags being an 
53 important source of nesting holes (Newton, 1994), such that in some communities secondary

54 cavity nesters rely mainly on cavities in decaying trees (Gibbons et al., 2002; Remm, Lohmus \&

55 Remm, 2006; Wesolowski, 2007).

56 Since the density of cavities is positively related to tree density and age (van Balen et al.,

57 1982), secondary cavity nesters may be less likely to find nesting sites in managed forests, from

58 where snags and old trees are often removed (Martin \& Li, 1992; Newton, 1994; Holt \& Martin,

59 1997; Martin \& Eadie, 1999; Martin, Aitken \& Wiebe, 2004; Saab, Dudley \& Thompson, 2004;

60 Sánchez, Cuervo \& Moreno 2007; Cornelius, 2008, Castro, Moreno-Rueda \& Hódar, 2009;

61 Goodenough, Elliot \& Hart, 2009). Suitable cavities are also scarcer in young than in old woods,

62 which are more structurally complex and have more cavities (Brawn \& Balda, 1988; Water, Noon

$63 \&$ Verner, 1990). To mitigate the effect of lack of nesting cavities on bird communities, nest

64 boxes are often placed in forest plantations where they may also favour the establishment of other

65 cavity-dependent species such as mammals, amphibians, reptiles (Newton, 1994) and as many as

66 thirty-nine invertebrate taxa, notably paper wasps and spiders (Mccomb \& Noble, 1982). Indeed,

67 many studies report greater densities of cavity-nesting birds in places where nest boxes have been

68 added (Brush, 1983; Brawn \& Balda, 1988; Waters, Noon \& Verner, 1990; Sánchez, Cuervo \&

69 Moreno, 2007; Miller, 2010; Dhondt, 2012). However, few reports include an initial count of

70 either birds or cavities (Brawn \& Balda, 1988; Miller, 2010; Aitken \& Martin, 2012), thus the

71 possibility that bird numbers differed between sites before the addition of nest boxes cannot

72 always be ruled out. Consequently, properly controlled experimental manipulations are needed to

73 determine the nature and extent of the effect of nest boxes on secondary cavity nesters (Brawn \&

74 Balda, 1988; Dhondt, 2012).

75 Here we report on an experimental manipulation in temperate Mexican forest where we 1)

76 assessed nest cavity availability, 2) added next boxes to trees in sampling points, and 3) counted 
77 the abundance of secondary cavity nesters and of breeding pairs both before and after the addition

78 of nest boxes. We conducted this study at the La Malinche National Park (LMNP), which

79 encompasses the upper part of La Malinche, an inactive volcano in central Mexico. In this area a

80 patchwork of forest management practices afforded a variety of environments in which to test our

81 predictions that there would be fewer cavities and secondary cavity nesting birds in young than in

82 a mature forest, and that adding nest-boxes to both forest types would increase the numbers of

83 secondary cavity nesters, especially in young forest.

\section{METHODS}

\section{Study area and experimental design}

86 With an extension of 45,711 ha, the La Malinche National Park is the most important protected

87 area in the state of Tlaxcala (Fig. 1). It harbours great biological diversity, including 27 mammal,

8869 bird, 11 reptile, and five amphibian resident species, and an abundance of Dikarya (formerly

89 Deuteromycota) fungi, Amebozoa (Myxomicetes) and plants. At least six secondary cavity

90 nesting bird species belonging to five families nest at La Malinche National Park; both Pygmy

91 (Sitta pygmaea) and White-breasted Nuthatches (Sitta carolinensis), House Wrens (Troglodytes

92 aedon), brown creepers (Certhia americana), Mexican Chickadees (Poecile sclateri) and Western

93 Bluebirds (Sialia mexicana; Howell \& Webb, 2005; Windfield, 2005). Fifty-one percent (=

$9423,612 \mathrm{ha}$ ) of the official park area has been claimed by local communities for growing crops

95 (mainly maize) and to expand their urban areas. The other half of the park is covered by young

96 deciduous (mostly below 2800 masl), young coniferous (restoration forest), or mixed mature

97 forest (Villers \& López, 2004). We established study plots in two contrasting vegetation types;

98 mixed mature forest, and forest at an advanced restoration stage of uniformly young conifer trees.

99 Each vegetation category was determined by both the species composition and the diameter of

100 the trees at breast height $(\mathrm{DBH})$. Mature forest plots were characterized by an average $\mathrm{DBH}>30$ 
$101 \mathrm{~cm}$ and a predominance of Abies religiosa, mixed with Pinus montezumae and P. hartwegii.

102 Young forest plots were characterized by an average $\mathrm{DBH} \leq 30 \mathrm{~cm}$ (c.f. Spies \& Franklin, 1991;

103 Lorimer, Dahir \& Nordheim, 2001) and dominated by P. hartwegii. Though other attributes can

104 be used to characterise forests (Weikel \& Hayes, 1999; Huhta et al., 2004; Martin, Aitken \&

105 Wiebe, 2004), we used the common practice of defining forest type based on DBH and tree 106 composition alone (Li \& Martin, 1991; Miller, 2010).

107 In 2009 we established one 24.25 ha study plot in each forest type (mature = M1; young =

108 Y1; Fig. 1). In 2011 we increased our sample by setting up two more plots per forest type (mature

$109=\mathrm{M} 2$ and M3; Young = Y2 and Y3); these were somewhat smaller (16.5 ha each) to

110 accommodate our recording schedule, and were composed of trees of different mean size than

111 those in the 2009 plots. The 2011 plots in mature forest contained fewer very thick trees (mean

$112 \mathrm{DHB}=39.53 \pm 11.20 \mathrm{~cm})$ than the 2009 mature-forest plot $($ mean $\mathrm{DBH}=66.03 \pm 31.32)$,

113 whereas the young forest plots, although still dominated by immature trees, contained more

114 mature trees in $2011($ mean $\mathrm{DBH}=31.20 \pm 9.52 \mathrm{~cm})$ than in $2009(26.97 \pm 8.14 \mathrm{~cm}$; see

115 supplementary material). Mean distance between plots was $4.3 \mathrm{~km}$. Plots were located in the

116 southern slope of La Malinche, at altitudes of 2856-3262 $\mathrm{m}$ a.s.1. (Fig. 1). Within each plot we

117 established sampling points $150 \mathrm{~m}$ apart (Fig. 2); plots established in 2009 had 12 points, and

118 those from 2011 had eight points. At each point we recorded the altitude, measured height and

119 DBH of every tree within a 25 m radius, and calculated tree density and fir/pine ratio.. A

120 discriminant function analysis based on DBH, tree height and altitude confirmed plot

121 membership to either young or mature forest plots $\left(F_{(6,69)}=13.4\right.$, Wilk's $\left.\lambda=0.4, P<0.0001\right)$. The

122 discriminant function correctly classified $93 \%$ of all sampling sites, and revealed significant

123 differences between the forests that we deemed mature and those we classified as young $(t=-9.4$,

$124 \mathrm{df}=54, P<0.0001)$. 


\section{Availability of cavities}

126 In 2009, to determine the availability of natural cavities in both types of forest, we counted all

127 cavities found in mature, dead or decaying trees at each point (tree categories as per Martin,

128 Norris \& Drever, 2006). We scanned 2243 trees in the two study plots using 10 x 42 binoculars.

129 This procedure, which is more expedient than following birds carrying nest materials or climbing

130 trees to survey cavities (Cockle, Martin \& Wiebe, 2008; Stojanovic et al., 2012), is conservative

131 because it likely underestimates the number of cavities found in large trees and dense foliage, and

132 small cavities are more difficult to detect in mature than in young forest (Koch, 2008). We

133 considered a cavity to contain an active nest if we observed an adult entering and remaining

134 inside the cavity for ten minutes or poking its head out on two or more occasions on different

135 days. We also recorded the species of all cavity-bearing trees and their DBH. In 2010 we did not

136 count cavities because we focused our efforts on installing and monitoring nest boxes. In 2011 we

137 surveyed the cavities in the original (2009) plots, and measured, whenever it was accessible (at a

138 height $<2 \mathrm{~m}$ ), the entrance height and diameter, and the width and the depth of the cavity. For

139 new cavities, we also recorded the tree species and $\mathrm{DBH}$.

\section{Abundance of secondary cavity nesting birds}

141 Twelve count points were homogeneously established within each of the 2009 plots (M1 and Y1)

142 and eight points in each of the 2011 plots (M2, M3, Y2, Y3) at the intersections of a $200 \times 200 \mathrm{~m}$

143 grid (Fig. 2). The points were located using a Garmin ${ }^{\mathrm{TM}}$ GPS (Bibby, Burgess \& Hill, 1992;

144 Ralph et al., 1996). In 2011 a row with four points was removed from the 2009 plots (M1 and

145 Y1) to homogenize the sampling scheme (eight points per plot) that year. A minimum distance of

$146200 \mathrm{~m}$ between points was chosen to minimise the risk of counting individual birds more than

147 once, based on the foraging behaviour of brown creepers during the breeding season, which takes

148 place within ca. $100 \mathrm{~m}$ around the nest (Franzred, 1985). 
150 These were carried out from 8:00 to 13:00 h by following a set of pre-established routes that

151 balanced both the time of day and the sequence in which different plots were visited. Point counts

152 lasted ten minutes (Miller, 2010), and 15 min were allotted to move between points. During

153 counts, every secondary cavity nester seen or heard within a 25m radius was recorded (point-

154 count survey methods followed Bibby, Burgess \& Hill, 1992; Ralph et al., 1993, see also

155 Manuwal \& Huff, 1897; Martin, Norris \& Drever, 2006) using a standardised surveying method

156 that consisted of systematically scanning each tree within the observation radius from top to

157 bottom using binoculars, starting at a haphazardly chosen direction and moving clockwise until

158 completing a circle. This method maximised the probability of spotting secondary cavity nesters

159 that normally forage on trunks (Franzred, 1985). All counts were made by the same observer

160 (CCL) and since each individual seen and/or heard was counted only once, each bird was deemed

161 to be an independent observation at each point.

\section{Nest box installation}

163 In November 2009 and in January 2011 we installed nest boxes in all of our experimental study

164 plots and monitored both the abundance of secondary cavity nesters and the breeding activity of

165 those using nest boxes. To accommodate the preferences of all the secondary cavity nesting

166 species present at La Malinche, we used two nest box designs; standard (intended to attract Sitta

167 spp., Troglodytes aedon and Poecile sclateri), and tree creeper nest box (based on a design at

168 www.birdfood.co.uk), to attract Certhia americana. All boxes were constructed from $1.5 \mathrm{~cm}$

169 thick pine plywood. Standard nest boxes had a forward-slanted roof, and measured internally

$17014.5 \times 12 \times 25$ to $30 \mathrm{~cm}$ (width, depth, height), with a $3 \mathrm{~cm}$ diameter entrance hole placed at the

171 middle of the frontal pane. Internally, the cuneiform boxes intended for tree creepers measured 
$17213 \times 12.5 \times 35 \mathrm{~cm}$ (width, depth, height) with a $3 \mathrm{~cm}$ triangular entrance at the top of the

173 (triangular) left side.

174 In 2009 we placed 80 nest boxes in eight of the 12 points in the young forest plot (Y1),

175 and 40 boxes in four of the 12 points in mature forest plot, five boxes of each type were placed at

176 each point (M1; Fig. 2A). We added twice as many boxes to young than to mature forest points so

177 that cavity availability would be the same in both forest types (see results). Nest boxes, which

178 were placed 10 m apart (Brush, 1983; Sánchez, Cuervo \& Moreno, 2007), were fastened with a

179 strap to a tree branch at the same height as natural cavities (between 5 and $10 \mathrm{~m}$ ). Four of the 12

180 points in the young forest and eight of the 12 points in the mature forest did not receive nest

181 boxes and acted as control points.

182 To allow comparison with other studies where an initial count of the birds was not carried

183 out, we also placed nest boxes in the M2-M3 and Y2-Y3 plots in January 2011. Nest boxes were

184 distributed in four of the eight points of each plot (Fig. 2B). Three boxes of each type were

185 placed at each count point, resulting in 24 nest boxes per plot per vegetation type. Again, the

186 remaining count points in each of the plots served as controls for the addition of nest boxes. In

1872010 and 2011, between mid-February and early-September, all boxes were checked fortnightly,

188 in the weeks when counts were not conducted, and weekly once evidence of nesting activity was

189 detected (mid-March and early-August). In the latter case we recorded the species, number of

190 eggs laid and number of fledglings produced of the birds using the nest box.

191 Permission to conduct this study was granted by the Mexican Ministry for the Environment

192 (Secretaría de Manejo y Aprovechamiento de los Recursos Naturales; SEMARNAT, permit 193 \#SGPA/DGVS/04677/10). 


\section{Statistical analyses}

195 Availability of cavities and abundance of secondary cavity nesting birds

196 Each point was deemed an experimental unit for the analyses (Ralph et al., 1993). We applied a $\chi^{2}$

197 homogeneity test to evaluate whether forest types differed in the number of trees with natural

198 cavities, and a goodness-of-fit $\chi^{2}$ test to evaluate whether the total number of natural cavities

199 differed between forest types.

200 Addition of nest boxes. We performed preliminary comparisons of total numbers of secondary

201 cavity nesters recorded on each bird count at each point in both forest types (M1, Y1) in 2009

202 using a t-test (after verifying normality and equality of variances). Then, the effect of the addition

203 of nest boxes was formally evaluated using a more complete approach that included the plots

204 established in 2010 - 2011. We constructed a generalized linear mixed-effects model (GLMM) to

205 detect whether the number of secondary cavity nesters was influenced by the addition of nest

206 boxes in each forest type. Our model included forest type (young or mature) and treatment (with

207 or without nest boxes), and their interaction as fixed effects. Random effects in the model were 1)

208 point identity and 2) number of visits that we performed to each point (as this varied with

209 breeding activity), both nested within year.

210 Due to the differences in the experimental design between 2009 and 2011, we

211 implemented an additional test comparing the number of secondary cavity nesters observed in

212 nest boxes versus control points in the plots added in 2011 (M2, M3, Y2, Y3), again using a

213 GLMM. This model included forest type (young or mature) and treatment (with or without nest

214 boxes) and their interaction as fixed effects. The number of visits to each point, nested within

215 point identity, was included as a random effect. Our data showed signs of both excess of zeros

216 and overdispersion with respect to a Poisson distribution; therefore, we constructed zero-inflated 
217 negative binomial GLMMs using the library glmmADMB for R (Bates, Maechler \& Bolker,

218 2011; Skaug et al., 2011). All statistical analyses were carried out with R software, v. 3.1.0.

\section{RESULTS}

\section{Availability of cavities and abundance of secondary cavity nesting birds}

221 Abundance of natural cavities. Young and mature forests had a similar number of trees with

222 cavities (Table 1: $\chi^{2}=2.2, \mathrm{df}=1, P=0.14$ ). However, as mature trees with cavities often had

223 more than one, there were significantly more total cavities in mature than in young forests

224 (goodness-of-fit tests contrasting with a distribution adjusted to the numbers of trees in both types

225 of forest; $\chi^{2}=9.5, \mathrm{df}=1, P=0.002$; Table 1 ). In 2011, cavity height was significantly higher in

226 mature than in young forest $(t=11.0, \mathrm{df}=45, P<0.0001)$, but had similar entrance diameter $(t=$

$2270, \mathrm{df}=39, P=1)$, and depth $(t=1.5, \mathrm{df}=39, P=0.16)$. Six cavities in mature orest were

228 inaccessible and thus were not measured. These comparisons relate to attributes of natural

229 cavities in 2011; most of the cavities measured that year were the same as those counted -but not

230 measured- in2009.

In 2009, 13 of the 50 (natural) cavities found in mature forest were occupied (four by $S$.

232 pygmea, five by T. aedon, two by P. sclateri, and two by C. americana). One of the 17 cavities

233 located in young forest were occupied (by T. aedon). However, young and mature forest had

234 similar proportion of cavities used (Fisher's exact test: $P=0.095)$. Of the cavities originally

235 found in 2009, thirteen in mature forest and seven in young forest were lost by 2011, mostly

236 because the trees containing them fell. Of the 37 cavities identified in 2009 in the mature forest

237 plots, five were again occupied by nesting birds in 2011 (two by S. pygmea, one by T. aedon, one

238 by $C$. americana, and one by Colaptes auratus), and two new cavities were identified as nest sites

239 (one occupied by S. mexicana and one by Melanerpes formicivorus). In the young forest, the 
240 cavity previously used in 2009 was again occupied in 2011 by nesting T. aedon (Fisher's exact

241 test: $P=1)$.

242 Bird counts. Although sightings were not abundant in either forest, we recorded a larger number

243 of secondary cavity nesters in mature $(x=11.0 \pm 7.0$ [sd] birds per site across 20 visits $)$ than in

244 young forest $(\mathrm{x}=5.3 \pm 4.8 ; t=-2.3, \mathrm{df}=22, P=0.03)$ in 2009 , consistent with our finding that

245 there were more nesting cavities available in mature than in young forest.

\section{Addition of nest boxes}

247 The number of secondary cavity nester birds sighted increased following installation of

248 nest boxes in both forest types $(P=0.05)$, and they appeared to be more abundant in the second

249 year after the boxes were added $(P<0.01)$. Forest type had no effect on the number of secondary

250 cavity nesters sighted after adding nest boxes (Table 2A; Fig. 3), and there was no interaction

251 between forest type and treatment (addition of nest boxes; GLMM: $\Delta$ deviance $_{2,10}=0.168, P$

$252=0.91)$.

253 In plots where nest boxes were added in 2011, there was a significant increase $(P<0.01)$

254 in sightings of secondary cavity nesters at points with nest boxes than at control points (Fig. 4).

255 Again, neither forest type, nor the interaction of forest type with treatment (presence/absence of

256 nest boxes) had an effect on the number of secondary cavity nesters seen (GLMM: $\Delta$ deviance $_{1,8}=$

257 1.842, $P=0.17$; Table 2B).

258 Nest box usage. None of the 40 nest boxes added to the mature forest plots in 2009 was occupied

259 in 2010, and only one was used by a pair of T. aedon in 2011. In contrast, 11 (14\%) of the 80

260 boxes added to young forest in 2009 were used (one by C. americana, two by P. sclateri, two by

261 T. aedon, and six by $S$. mexicana). The use of our nest boxes by $S$. Mexicana was unexpected,

262 since the entrance to our boxes was deliberately made small to discourage species of this size. A 
263 similar number of boxes (12) was occupied in 2011 in young forest, again mostly by $S$. mexicana

264 ( $n=7)$, but also by P. sclateri $(n=2)$, and by S. pygmaea, S. carolinensis and T. aedon (one box

265 each). After fledging one brood, the boxes used by P. sclateri and S. carolinensis were occupied

266 by $S$. mexicana, and the box used by $S$. mexicana was subsequently occupied by $T$. aedon.

267 In plots incorporated in 2011, the picture was somewhat different; in the first year following nest

268 box installation six out of the 48 boxes established in mature forest were occupied by T. aedon.

269 Similarly, in young forest plots incorporated in 2011, ten out of the 48 boxes installed were used

270 during the first year after installation (five by $S$. mexicana and five by $T$. aedon). In contrast to

271 others studies (i.e. Jantti et al., 2001), tree creeper did not use the nest boxes designed to

272 accommodate their particular nesting habits. We only had one pair of Certhia americana

273 occupying our boxes, and it nested in a standard nest box. Each nest box occupied represents one

274 breeding pair, and all boxes had fledgling success $>0$, as we recorded no events of nest predation

275 or usurpation, and no nests were abandoned that had settled in our boxes.

\section{DISCUSSION}

277 There is continued interest in evaluating the availability and suitability of nesting sites in

278 different environments because these often limit the local diversity of species and the number of

279 breeding pairs (Newton, 1994; Martin, Aitken \& Wiebe 2004; Wesolowski, 2007; Cockle, Martin

280 \& Drever, 2010). Before installing artificial nest boxes, we found that secondary cavity nester

281 sightings were more frequent in mature than in young forest $(P=0.03)$, perhaps related to the

282 availability of natural cavities. We also found a higher percentage of natural cavities occupied by

283 secondary cavity nesters in mature than in young forest, although the difference was not

284 significant. This figure (26\%) is much lower than those from northern temperate forests $(61-93 \%$

285 van Balen et al., 1982; 67\% Ingold \& Ingold, 1984; 57 \% Peterson \& Gauthier, 1985), but higher 
286 than in neotropical habitats, where decay promotes the production of cavities- (c.f.5\% in

287 Argentinean Atlantic forest [Cockle, Martin \& Wiebe, 2008]; 2\% in Peruvian Amazon forest

288 [Brightsmith, 2005]). Although located well within the tropics, the mature forest at La Malinche

289 is more similar in both climate and biological community to northern temperate forests than

290 tropical forests, thus the low proportion of occupied cavities may indicate a low population

291 density of secondary cavity nesters, rather than a superabundance of cavities as seen in warmer

292 and moister forests.

293 Breeding populations of cavity nesting birds may be limited by other factors including

294 territoriality and interspecific competition for nest sites (Newton, 1994; 1998; Dhondt, 2012) or

295 sites vulnerable to predation (Nilsson, 1984). There is no information on territory size or

296 territorial behaviour of any bird species at La Malinche, thus we cannot rule out the possibility

297 that the small proportion of cavities used in the mature forest is due to territoriality. However, we

298 think that this is unlikely because adjacent nest boxes in young forest were often occupied, both

299 by the same and by different species. Although some nest boxes were used twice by the same or 300 different species $(n=3)$, we did not observed any agonistic behaviour or other forms of inter- or

301 intra-specific usurpation.

302 Cavity abundance alone may be insufficient to explain cavity use; as Lohmus \& Remm

303 (2005) have argued, cavity quality (e.g. height, size, depth, degree of tree decay, etc.), together

304 with abundance, determine the real availability of appropriate nesting holes (see also Rendell \&

305 Robertson, 1989; Wiebe \& Swift, 2001; Cockle, Martin \& Wiebe, 2008; Cockle, Martin \&

306 Robledo, 2012). We do not have sufficient data to estimate the proportion of natural cavities that

307 are suitable for nesting in the mature forest. However, over the two years when nest boxes were

308 available, only one was occupied in the mature forest, thus scarcity of suitable cavities does not

309 appear to be limiting cavity use by secondary cavity nesters in that forest. Conversely, the

310 significant increase of sightings of secondary cavity nesters in the young forest following the 
311 addition of nest boxes indicates that in this habitat nest site availability is indeed a limiting factor

312 for the populations of those birds.

313 The higher occupancy of nest boxes in young forest (31.95\%) compared to the mature

314 forest $(8.3 \%)$ was to a degree driven by the readiness with which $S$. mexicana took to breeding in

315 them. This is similar to the findings of Miller (2010) that bluebirds readily colonise forest gaps,

316 forest edges, and other plant communities with few trees, as is true in the La Malinche young

317 forest. However, another five species successfully nested in the boxes that we provided, thus the

318 benefits of this practice extended to their populations. Given that substantial sections of La

319 Malinche are occupied by young forest, it is likely that the population size of secondary cavity

320 nesters is much smaller than this habitat could potentially maintain.

321 Our data provide additional support for the hypothesis that in managed/secondary forest, the

322 populations of secondary cavity-nesting birds are limited by the scarcity of cavities (Brawn \&

323 Balda 1988; Waters, Noon \& Verner, 1990; Tomasevic \& Estades, 2006). As pristine

324 environments disappear and natural woodland gives way to managed forest, the structure of its

325 biological communities will largely depend on the decisions we make to protect and increase

326 biological diversity (Janzen, 1998). One way in which we can contribute to promoting

327 community richness in managed forests is by supplementing key resources that are lacking or

328 scarce in those environments, such as appropriate cavities for nesting. These, in addition to

329 increasing the density of insectivorous cavity nesting birds, can promote the fitness of the plants

330 in which they forage, by substantially reducing the number of insects on the plants (Sanz, 2001).

331 Forest management practices that promote the conservation of insectivorous birds are

332 fundamental for the maintenance of forest productivity, through controlling of the populations of

333 pest insects (Marquis \& Whelan, 1994).

334 Forest management programs throughout Latin America currently do not, but should

335 include, the addition of nest boxes to forest plantations. Because nest boxes increase bird 
336 numbers and species diversity, their addition should be encouraged to generate the benefits 337 associated with a richer bird community.

\section{ACKNOWLEDGEMENTS}

339 Several undergraduate students from the Tlaxcala (UAT), Puebla (BUAP) and National (UNAM)

340 autonomous universities helped in different phases of the fieldwork. We thank A. Salinas-

341 Melgoza and A. Ríos-Chelén for their feedback on drafts, and G. Moreno-Rueda and an

342 anonymous referee further helped improving the manuscript. L. Kiere and O. Sánchez-Macouzet

343 advised on the statistical analyses. CCL was supported by a scholarship from CONACyT (45901)

344 to conduct $\mathrm{PhD}$ studies in the Doctorado en Ciencias Biomédicas, Universidad Nacional

345 Autónoma de México; the present paper is submitted in partial fulfilment of the program's

346 requirements.

\section{REFERENCES}

348 Aitken KEH, Martin K. 2012. Experimental test of nest-site limitation in mature mixed forests 349 of Central British Columbia, Canada. Journal of Wildlife Management 76:557-565.

350 Bates D, Maechler M, Bolker B. 2011. 1me4: Linear Mixed-Effects Models Using S4 Classes. R Package, version 0.999375-42, http://CRAN.Rproject.org/package=lme4.

Bibby CJ, Burgess ND, Hill D. 1992. Bird census techniques. British Trust for Ornithology. Academic Press. London.

354 Brawn JD, Balda RP. 1988. Population biology of cavity nesters in Northern Arizona: do nest sites limit breeding densities? Condor 90: 61-71. 
356 Brightsmith DJ. 2005. Competition, predation and nest niche shifts among tropical cavity nesters: ecological evidence. Journal of Avian Biology 36: 74-83.

358 Brush T. 1983. Cavity use by secondary cavity-nesting birds and response to manipulations. $359 \quad$ Condor 85: 461-466.

360 Casas-Crivillé A, Valera F. 2005. The European bee-eater (Merops apiaster) as an ecosystem 361 engineer in arid environments. Journal of Arid Environments 60: 227-238.

362 Castro J, Moreno-Rueda G, Hódar JA. 2010. Experimental test of postfire management in pine 363 forests: Impact of salvage logging versus partial cutting and nonintervention on bird$364 \quad$ species assemblages. Conservation Biology 24: 810-819.

365 Cockle K, Martin K, Wiebe K. 2008. Availability of cavities for nesting birds in the Atlantic 366 forest, Argentina. Ornitologia Neotropical 19: 269-278.

367 Cockle K, Martin K, Drever M. 2010. Supply of tree-holes limits nest density of cavity nesting 368 birds in primary and logged subtropical Atlantic forest. Biological Conservation 143: $369 \quad 2851-2857$.

370 Cockle K, Martin K, Robledo G. 2012. Linking fungi, trees, and hole-using birds in a 371 Neotropical tree-cavity network: Pathways of cavity production and implications for 372 conservation. Forest Ecology and Management 264: 210-219.

373 Cornelius C. 2008. Spatial variation in nest-site selection by a secondary cavity-nesting in a 374 human-altered landscape. Condor 110: 615-626.

375 Cornelius C, Cockle K, Politi N, Berkunsky I, Sandoval VO, Rivera L, Hunter MJr, Martin

376 K. 2008. Cavity-nesting birds in neotropical forest: cavities as a potentially limiting 377 resource. Ornitologia Neotropical 19: 253-268. 
378 Dhondt AA. 2012. Interspecific Competition in Birds (Vol. 2). Oxford Avian Biology.

379 Franzreb KE. 1985. Foraging ecology of brown creepers in a mixed-coniferous forest. Journal $380 \quad$ of Field Ornithology 56: 9-16.

381 Gibbons P, Lindenmayer DB, Barry SC, Tanton MT. 2002. Hollow selection by vertebrate 382 fauna in forests of southeastern Australia and implications for forest management. 383 Biological Conservation 103: 1-12.

384 Goodenough AE, Elliot SL, Hart AG. 2009. Are nest sites actively chosen? Testing a common 385 assumption for three non-resource limited birds. Acta Oecologica 35: 598-602.

Holt RF, Martin K. 1997. Lanscape modification and patch selection: the demography of two secondary cavity nesters colonizing clearcuts. Auk 114: 443-455.

Howell S, Webb S. 2005. A guide to the birds of Mexico and Northern Central America. Oxford University Press.

Huhta E, Aho T, Jantti A, Suorsa P, Kuitunen M, Nikula A, Hakkarainen H. 2004. Forest fragmentation increases nest predation in the Eurasian treecreeper. Conservation Biology 18: $148-155$.

Ingold DJ, Ingold DA. 1984. A study of possible niche preferences of cavity-nesting birds in the Colorado Rockies. NMOS Bulletin New Mexico Ornithological Society 12: 1-9. abundance of red wood ants Formica rufa is associated with the body condition of nestlings in the Eurasian treecreper Certhia familiaris. Journal of Avian Biology 38:619624. 
399 Janzen DH. 1998. Gardenification of wildland nature and the human footprints. Science 279:

$400 \quad 1312-1313$.

401 Koch AJ. 2008. Errors associated with two methods of assessing tree hollow occurrence and 402 403 abundance in Eucalypts obliqua forest, Tasmania. Forest Ecology Management 255: 674-

Lambrechts MM, Schatz B, Borgault P. 2008. Interactions between ants and breeding Paridae in two distinct Corsican oak habitats. Folia Zoologica 57: 264-268.

Lambrechts MM, Adriaensen F, Ardia DR, Artemyev AV, Atiénzar F, Banbura J, Barba E, Bouvier JC, Camprodon J, Cooper CB, Dawson RD, Eens M, Eeva T, Faivre B, Garamszegi LZ, Goodenough AE, Gosler AG, Grégoire A, Griffith SC, Gustafsson L, Johnson S, Wojciech K, Keiss O, Llambias PE, Mainwaring MC, Mand R, Massa B, Mazgajski TD, Møller AP, Moreno J, Naef-Daenzer B, Nilsson JA, Norte AC, Orell M, Otter KA, Park CR, Perrins CM, Pinowski J, Porkert J, Potti J, Remes V, Richner H, Rytkönen S, Shiao MT, Silverin B, Slagsvold T, Smith HG, Sorace A, Stennig MJ, Stewart I, Thompson CF, Tryjanowski P, Török J, Noordwijk AJV,

417 Li P, Martin TE. 1991. Nest-site selection and nesting success of cavity-nesting birds in high Winkler D, Ziane N. 2010. The desing of artificial nestboxes for the study of secondary hole-nesting birds: a review of methodological inconsistencies and potential biases. Acta Ornithologica 4: 1-26. cavity-rich habitat. Acta Oecologica 27: 125-128. 
421 Lorimer CG, Dahir SE, Nordheim EV. 2001. Tree mortality rates and longevity in mature and old-growth hemlock-hardwood forests. Journal of Ecology 89:960-971.

423

424

425

426

Manuwal DA, Huff MH. 1987. Spring and winter bird populations in a douglas-fir forest sere. Journal of Wildlife Management 51: 586-595.

Marquis RJ, Whelan CJ. 1994. Insectivorous birds increase growth of white oak through consumption of leaf-chewing insects. Ecology 75: 2007-2014.

Martin K, Eadie JM. 1999. Nest webs: a community-wide approach to the management and conservation of cavity-nesting forest birds. Forest Ecology and Management 115: 243257.

Martin TE, Li P. 1992. Life history traits of open- vs. cavity-nesting birds. Ecology 72: 579-592.

Martin K, Aitken K, Wiebe K. 2004. Nest site and nest web for cavity-nesting communities in interior British Columbia, Canada: Nest characteristics and niche partitioning. Condor 106: 5-19.

Martin K, Norris A, Drever M. 2006. Effects of bark beetle outbreaks on avian biodiversity in the British Columbia interior: Implications for critical habitat management. BC Journal of Ecosystems and Management 7: 10-24.

Mccomb WC, Noble RE. 1982. Invertebrate use of natural tree cavities and vertebrate nest boxes. The American Midland Naturalist 107:163-172.

Miller KE. 2010. Nest-site limitation of secondary cavity-nesting birds in even-age southern pine forests. Wilson Bulletin 122: 126-134. 
441 Newton I. 1994. The role of nest-sites in limiting the numbers of hole-nesting birds: a review. 442 Biological Conservation 70: 265-276.

443 Newton I. 1998. Population limitation in birds. Academic Press.

444 Nilsson SG. 1984. The evolution of nest-site among hole-nesting birds: the importance of nest $445 \quad$ predation and competition. Ornis Scandinavica 15:167-175.

446 Peterson B, Gauthier G. 1985. Nest site use by cavity-nesting birds of the cariboo parkland, 447 British Columbia. Wilson Bulletin 97: 319-331.

Ralph JC, Geupel GR, Pyle P, Martin TE, DeSante DF, Milá B. 1996. Manual de métodos de campo para el monitoreo de aves terrestres. Gen. Tech. Rep. PSW-GTR-159. Albany, CA: Pacific Southwest Research Station.

Remm J, Lohmus A, Remm K. 2006. Tree cavities in riverine forests: What determines their 453 occurrence and use by hole-nesting passerines? Forest Ecology Management 221: 267277.

Rendell WB, Robertson RJ. 1989. Nest-site characteristics, reproductive success and cavity availability for Tree Swallows breeding in natural cavities. Condor 91: 875-885.

Saab VA, Dudley J, Thompson WL. 2004. Factors influencing occupancy of nest cavities in recently burned forests. Condor 106: 20-36.

Sánchez S, Cuervo JJ, Moreno E. 2007. Suitable cavities as a scarce resource for both cavity and non-cavity nesting birds in managed temperate forests. A case study in the Iberian peninsula. Ardeola 54: 261-274. 
461 Sanz JJ. 2001. Experimental increased insectivorous bird density result in a reduction of caterpillar density and leaf damage to Pyrenean oak. Ecological Research 16: 387-394.

463

Skaug H, Fournier D, Nielsen A, Magnusson A, Bolker B. 2011. glmmADMB: Generalized Linear Mixed Models Using AD Model Builder. R Package, version 0.7, http://glmmadmb.r-forge.r-project.org, http://admb-project.org.

Spies TA, Franklin JF. 1991. The structure of natural young, mature, and old-growth douglasfir forest in Oregon and Washington. U.S. Department of Agriculture, Forest Service Pacific Northwest Research Station.

Stojanovic D, Webb M, Roshier D, Saunders D, Heinsohn R. 2012. Ground-based survey methods both overstimate and understimate the abundance of suitable tree-cavities for the endangered Swift Parrot. Emu. 112:350-356.

Swallow SK, Gutierrez RJ, Howard RA. 1986. Primary cavity-site selection by birds. Journal of Wildlife Management 50: 576-583.

Tomasevic JA, Estades CF. 2006. Stand attributes and the abundance of secondary cavitynesting birds in southern beech (Nothofagus) forests in south-central Chile. Ornitología Neotropical 17: 1-14.

Van Balen JH, Booy CJH, Franeker JA van, Osieck ER. 1982. Studies on hole- nesting birds in natural nest sites. 1. Availability and occupation of natural nest sites. Ardea 70: 1-24.

Villers L, López J. 2004. Comportamiento del fuego y evaluación del riesgo por incendios en las áreas forestales de México: un estudio en el volcán la Malinche. In: Villers L, López J, eds. Incendios forestales en México, métodos de evaluación. México: UNAM, 61-78. 
482 Waters JR, Noon BR, Verner J. 1990. Lack of nest site limitation in a cavity-nesting bird 483 community. Journal of Wildlife Management 54: 239-245.

484 Weikel JM, Hayes JP. 1999. The foraging ecology of cavity-nesting birds in young forests of the 485 northern coast range of Oregon. Condor 101: 58-66.

486 Wesolowski T. 2007. Lessons from long-term hole-nester studies in a primeval temperate forest. 487 Journal of Ornithology 148: 395-405.

488 Wiebe KL, Swift TL. 2001. Clutch size relative to tree cavity size in Northern Flickers. Journal of Avian Biology 32: 167-173.

490

Windfield JC. 2005. Aves. In: Fernández FJA, López-Domínguez JC, eds. Biodiversidad del Parque Nacional Malinche, México, 115-136. 
492

\section{Table 1: Availability of natural cavities}

494 Numbers and characteristics of natural cavities found in the different types of forest each year

495 (mean $\pm \mathrm{sd}[\min -\max ])$.

\begin{tabular}{|c|c|c|c|c|}
\hline \multirow{2}{*}{ Forest } & \multicolumn{2}{|c|}{2009} & \multicolumn{2}{|c|}{2011} \\
\hline & Mature & Young & Mature & Young \\
\hline $\begin{array}{l}\text { Number of trees with } \\
\text { cavities }\end{array}$ & 22 & 10 & 21 & 6 \\
\hline Total number of cavities & 50 & 17 & 37 & 10 \\
\hline DBH of trees with cavities & $\begin{array}{c}60.90 \pm 38.65 \\
10.82-177.39\end{array}$ & $\begin{array}{l}60.35 \pm 16.95 \\
23.25-90.76\end{array}$ & $\begin{array}{c}97 \pm 14.6 \\
42.3-139.5\end{array}$ & $\begin{array}{c}65.05 \pm 24.95 \\
14.6-85.0\end{array}$ \\
\hline Cavity height (m) & --- & --- & $\begin{array}{c}6.4 \pm 1.5 \\
1.83-10.2\end{array}$ & $\begin{array}{l}1.14 \pm 0.23 \\
1.11-1.17\end{array}$ \\
\hline Entrance diameter $(\mathrm{cm})$ & --- & --- & $\begin{array}{l}5 \pm 0.33 \\
4.3-5.6\end{array}$ & $\begin{array}{c}5 \pm 2.05 \\
3.5-9\end{array}$ \\
\hline Vertical depth $(\mathrm{cm})$ & --- & --- & $\begin{array}{l}9.5 \pm 1.2 \\
5.6-11\end{array}$ & $\begin{array}{c}10.13 \pm 0.67 \\
9.3-11.3\end{array}$ \\
\hline $\begin{array}{l}\text { Condition of tree with } \\
\text { cavities }\end{array}$ & & & & \\
\hline Mature & 1 & 6 & 4 & 3 \\
\hline $\begin{array}{l}\text { Snag } \\
\text { Dead }\end{array}$ & $\begin{array}{c}2 \\
19\end{array}$ & $\begin{array}{l}1 \\
3\end{array}$ & $\begin{array}{c}1 \\
16\end{array}$ & $\begin{array}{l}0 \\
3\end{array}$ \\
\hline $\begin{array}{r}\text { Species of tree with cavities } \\
\text { Pine } \\
\text { Oak }\end{array}$ & $\begin{array}{c}21 \\
1\end{array}$ & $\begin{array}{c}10 \\
0\end{array}$ & $\begin{array}{c}21 \\
0\end{array}$ & $\begin{array}{c}6 \\
0\end{array}$ \\
\hline
\end{tabular}


496 Table 2: Results of generalized linear mixed-effects models (GLMMs).

497 The addition of nest boxes had a positive effect on the number of secondary cavity-nesting birds

498 in both 2010 and 2011 (A) but forest type did not (B). We used a zero-inflated negative binomial

499 error distribution.

\begin{tabular}{lccrr}
\hline Parameter & Estimate & Se & $Z$ & \\
& & & & \\
& & & & \\
A) Number of SCNs 2010-2011 & & & \\
Intercept & -0.50 & 0.19 & -2.65 & $<0.01$ \\
Mature & 0.21 & 0.16 & 1.34 & 0.18 \\
Boxes 2010 & 0.37 & 0.19 & 1.95 & 0.05 \\
Boxes 2011 & 0.99 & 0.19 & 5.20 & $<0.01$ \\
& & & & \\
B) Number of SCNs in plots 2011 & & & & \\
Intercept & -0.47 & 0.23 & -2.06 & 0.04 \\
Mature & 0.15 & 0.17 & 0.88 & 0.38 \\
Boxes & 0.95 & 0.17 & 5.58 & $<0.01$ \\
\hline
\end{tabular}




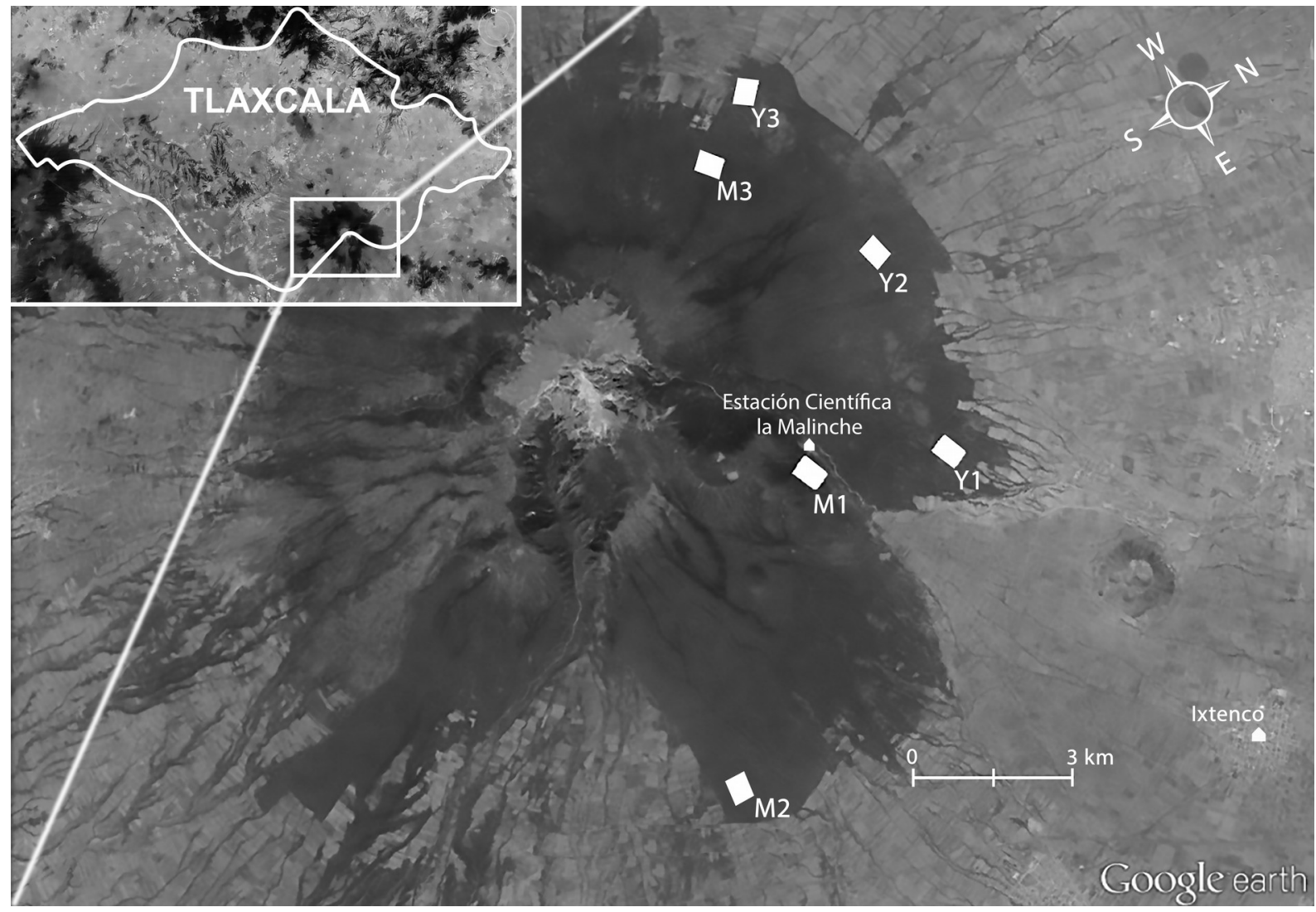

\section{Figure 1: Study location.}

501 Aerial view of La Malinche (Google Earth), located in Tlaxcala State (insert). White polygons

502 show our plots in mature (M1 M2, and M3) and young forest (Y1, Y2, and Y3). 
A) 2009

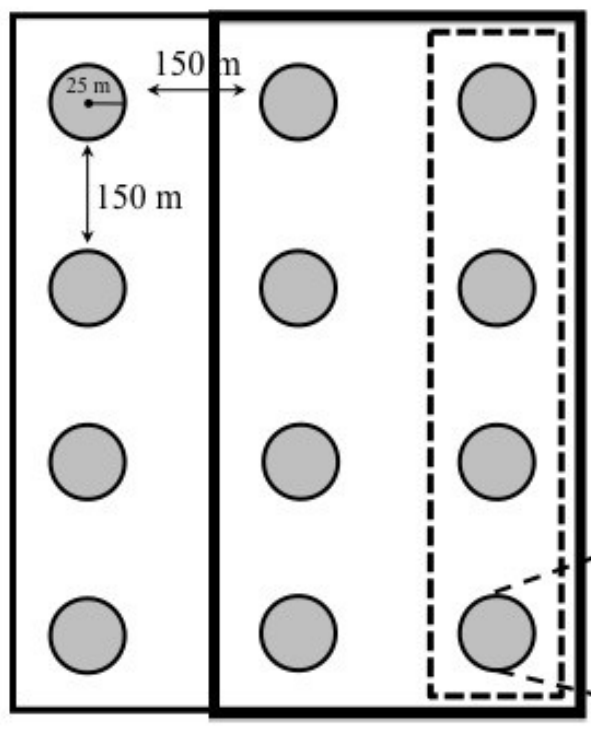

29.25 ha
B) 2011

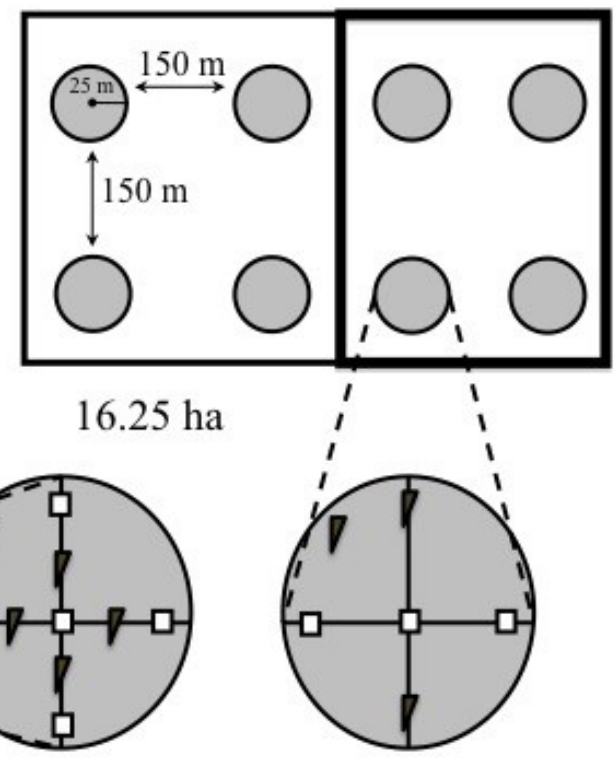

\section{Figure 2: Study design.}

504 Schematic representation of our plots showing the distribution of the $25-\mathrm{m}$ radius count points

505 within them. A) Point counts in plots established in 2009 were carried out in three rows of four

506 points each. In 2009, mature forest plots were supplemented with nest boxes at four points

507 (dashed box), while young forests were supplemented at eight points (bold box). B) In smaller

508 plots established in 2011, point counts were conducted in two rows of four points each, and nest

509 boxes were added at four of the eight points (bold box) in both forest types. Within each point,

510 two nest box types were installed:

$511(\square=$ standard boxes; $\quad \nabla=$ tree creeper boxes for Certhia $)$. 


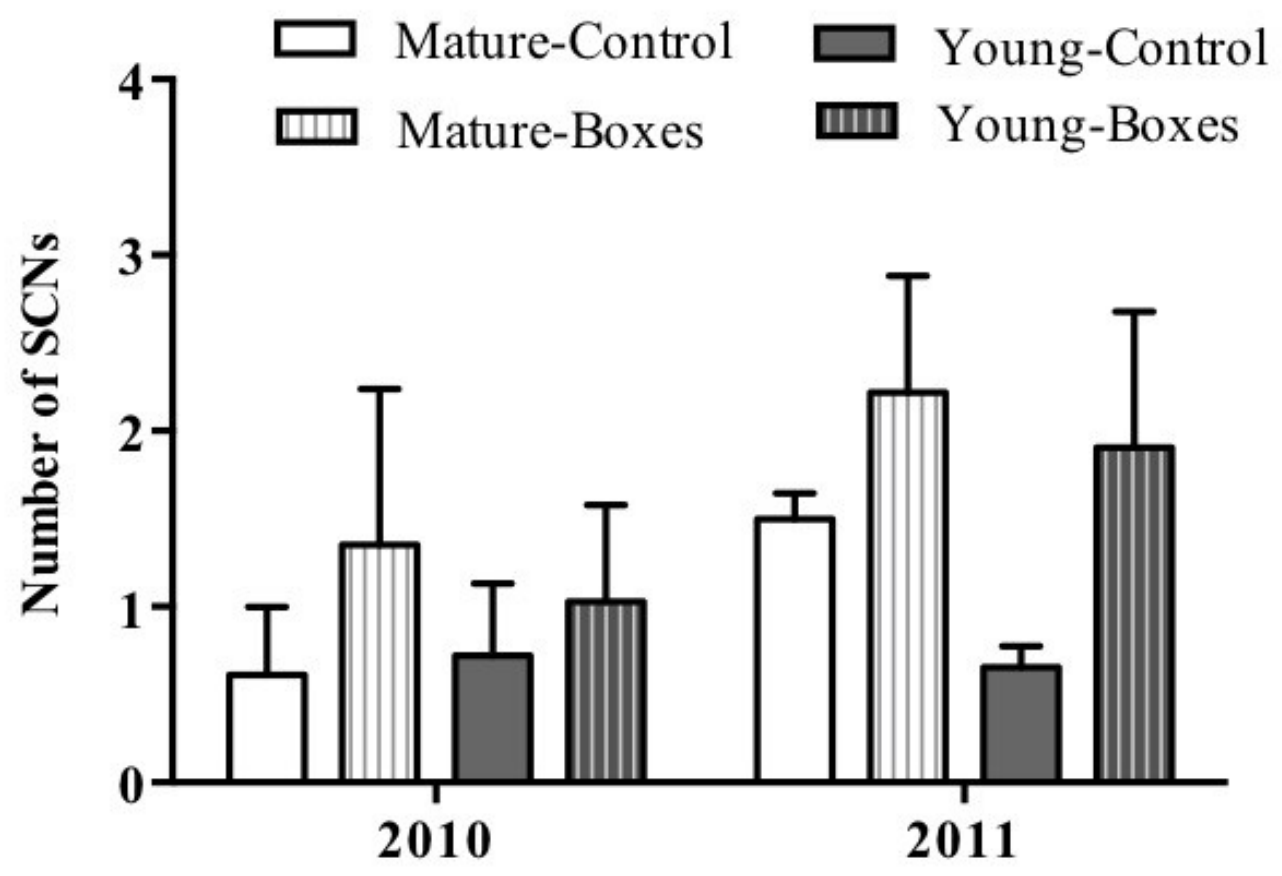

512 Figure 3: Effect of nest box installation on number of birds

513 Mean + SE number of secondary cavity-nesting birds (SCNs) in the study plots with or without

514 nest boxes. SCNs were sighted more often at the points where nest boxes were added in both

515 types of forest $(P=0.05)$, and they appeared to be more abundant in the second year after the 516 boxes were added $(P<0.01)$. 


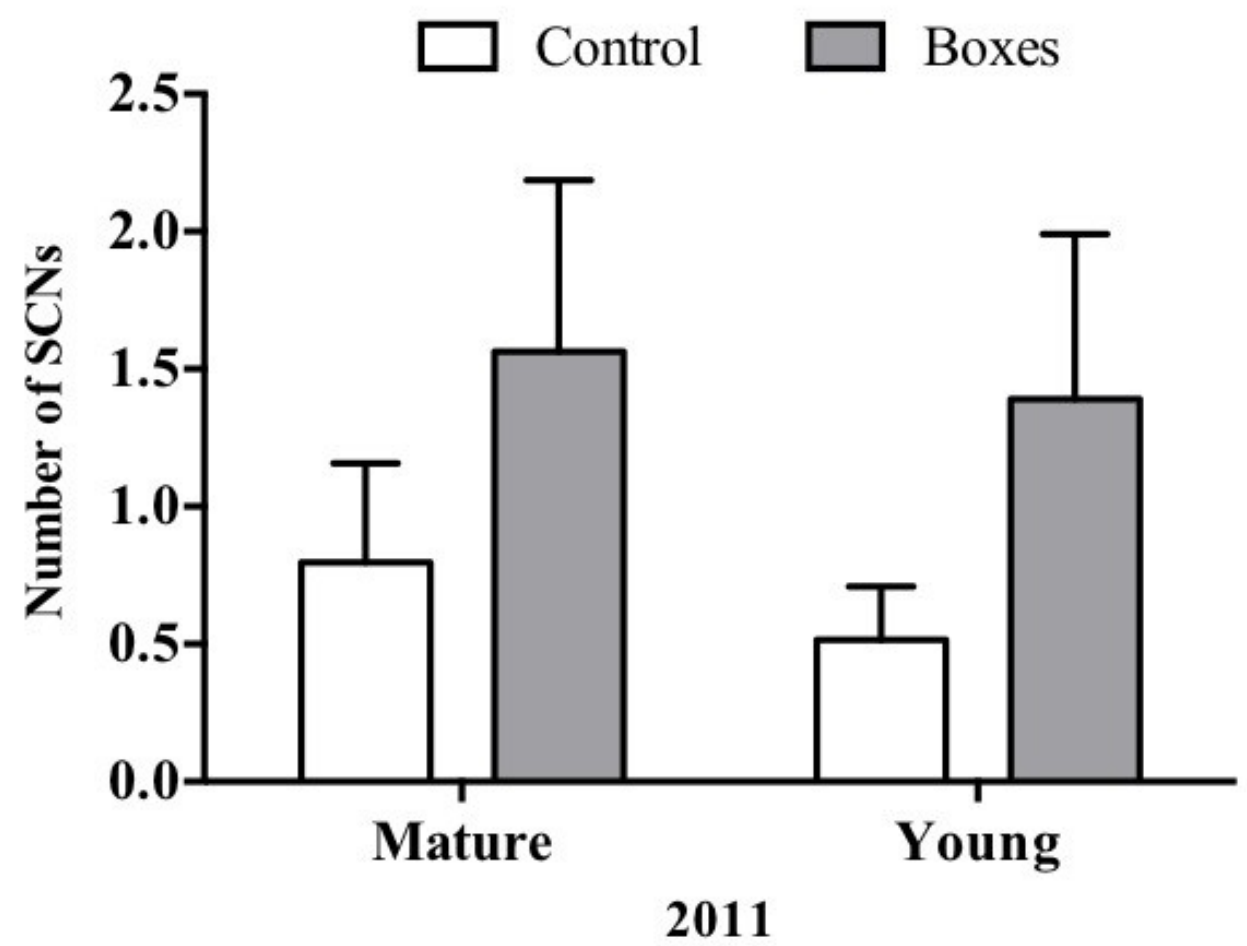

517 Figure 4. Plots established in 2011 for each forest type

518 In 2011, Mean + SE number of SCNs per count point in plots with or without nest boxes. SCNs

519 were more often sighted in the points where nest boxes were added in both types of forest $(P<$ $5200.01)$ 